\title{
Research on the Influence of Population Structure on Economic Growth: Based on the Provincial Panel Data Model
}

\author{
Shichang Shen, Jianmei Shen \\ School of Mathematics and Statistics, Qinghai Nationalities University, Xining, China \\ Email: 13909785766@163.com
}

How to cite this paper: Shen, S.C. and Shen, J.M. (2021) Research on the Influence of Population Structure on Economic Growth: Based on the Provincial Panel Data Model. Journal of Applied Mathematics and Physics, 9, 941-946.

https://doi.org/10.4236/jamp.2021.95064

Received: March 29, 2021

Accepted: May 16, 2021

Published: May 19, 2021

Copyright $\odot 2021$ by author(s) and Scientific Research Publishing Inc. This work is licensed under the Creative Commons Attribution International License (CC BY 4.0).

http://creativecommons.org/licenses/by/4.0/

\begin{abstract}
In recent years, the international environment and conditions of China's economic development have undergone profound and complex changes, but in the middle and long term, China's economy has been maintaining a stable medium-high speed development. It is remarkable that population changes bring about changes in economic development; especially the aging of the population has a particularly significant impact on economic growth. Therefore, based on the inter-provincial panel data of 31 provinces and municipalities from 2011 to 2019, this paper mainly studies the impact of population change on economic growth by establishing a solid fixed effect model. The results show that there is a long-term equilibrium relationship between population structure and economic growth, and population structure has a significant positive impact on economic development. In addition, there are regional differences in the positive and significant relationship between the two.
\end{abstract}

\section{Keywords}

Population Change, Economic Growth, Fixed Effects

\section{Introduction}

Since the reform and opening up, China's population structure has undergone a historic change, followed by a rapid economic progress. But the population and the aggravation of aging makes economic development lack of power. Based on this, You Shibing and Cai Yuanfei [1] (2017) constructed a panel vector autoregressive model using the provincial panel data from 2000 to 2013, which explained the problem that population aging is not conducive to economic development, and the authors point out that both direct and indirect effects of popu- 
lation aging are detrimental to economic growth. Di Re A Ha [2] (2020) from the perspective of demography and family planning, China's political and economic system reform, elaborated the adverse effects of population aging on economic development and effective solutions. Research shows that population aging as one of the main factors affecting the process of socialist modernization construction, has a direct impact on economic development. Therefore, the relationship between the two should be comprehensively controlled, and the disadvantages should be turned into advantages to promote economic development. Chen Jiamin [3] (2020) analyzed the two-way adverse effects between population aging and economic growth in Guangdong Province based on the VECM model. He finds that population ageing depresses economic growth in the short run, but boosts it in the long run. Guo Han, Ren Baoping [4] (2014) studied demographic dividend and its change and the transformation of economic development mode through empirical analysis from the perspective of economics. The results show that the demographic dividend change has an impact on economic development through four dimensions: capital formation, labor supply, human capital accumulation and labor allocation efficiency. This paper uses Stata15 software [5] and Eviews10 software [6] to study the panel data of 31 provinces and autonomous regions, so as to get the influence degree of population change on economic growth.

\section{Theoretical Basis}

The general form of panel data entity fixed model is as follows:

$$
y_{i t}=\delta+\lambda_{i}+\sum_{k=2}^{k} \beta_{k} x_{k i t}+\mu_{i t}
$$

The null hypothesis of the model is that under the null hypothesis, we can get the following this formula:

$$
F=\frac{(R R S S-U R S S) /(N-1)}{U R S S /(N T-N-K+1)} \sim F(N-1, N(T-1)-K+1)
$$

where, RRSS is the sum of regression residuals in the mixed model, and URSS is the sum of regression squares in the solid fixed effect model. $N$ is the number of cross-sections, $K$ is the number of explanatory variables, and $T$ is the number of time points.

\section{Empirical Analysis}

\subsection{Data Selection and Explanation}

In this paper, elderly population dependency ratio and regional per capita GDP were selected as explanatory variables and explained variables, expressed by EDR and GDP respectively. Economic growth can be measured in terms of gross domestic product (GDP) and gross domestic product (GDP) per capita. Here we use GDP per capita. Before the establishment of the model, the natural logarithm transformation of each data can not only eliminate heteroscedasticity but also 
make the data series more stable. First, the data are statistically described, as shown in Table 1.

\subsection{Unit Root Test}

Panel unit root test has its own methods. In this paper, LLC、IPS、ADF and PP-fisher are used to analyze the stability of the data to ensure the stability of the data and avoid the occurrence of false regression or false regression. The output results are show in Table 2. Table 2 shows that the two sequences after first-order difference reject the null hypothesis at the $5 \%$ level, so the data series is stable.

\subsection{Co-Integration Test}

$I(1)$ sequence of $\triangle \operatorname{In} G D P$ and $\triangle \operatorname{In} Q$ Complete the conditions of the Co-integration integration test, the following the two sequences with co-integration analysis, the results are shown in Table 3 . It is not difficult to see from Table 3 that the $P$ values of Perpdroni test, Kao test and joint distribution test mostly reject the null hypothesis. That is to say, at the $5 \%$ confidence level, these two data series have a co-integration relationship, that is, there is a long-term equilibrium relationship between population change and economic growth.

\subsection{Model test}

\subsubsection{Likelihood Ratio Test}

The null hypothesis of Likelihood Ratio (LR) test is that the model selection of fixed effect is redundant. As cab be seen from the test results in Table 4, at the $5 \%$ confidence level, the value of F statistic is 0 , and the value of LR statistic also 0 , which indicates that the model rejects the null hypothesis and further indicates

Table 1. Descriptive analysis of panel data.

\begin{tabular}{cccccc}
\hline Variables & Observations & Mean & Std. Dev. & Minimum & Maximum \\
\hline GDP & 279 & $23,132.21$ & $19,690.16$ & 611.5 & $107,986.9$ \\
EDR & 279 & 13.8319 & 3.410124 & 6.7 & 23.8 \\
\hline
\end{tabular}

Table 2. Unit root test of panel data.

\begin{tabular}{ccccc}
\hline Variables & LLC & IPS & ADF & PP-Fisher \\
\hline LNGDP & -8.6656 & 0.77555 & 70.0251 & 124.816 \\
& $(0.0000)^{\star *}$ & $(0.7810)^{\star *}$ & $(0.2263)^{\star *}$ & $(0.0000)^{\star *}$ \\
$\Delta$ LNGDP & -23.585 & -6.01438 & 146.28 & 93.7781 \\
& $(0.0000)^{\star *}$ & $(0.0000)^{\star *}$ & $(0.0000)^{\star *}$ & $(0.0057)^{\star *}$ \\
LNEDR & -1.36388 & 3.89141 & 30.8036 & 45.0248 \\
& $(0.0863)^{\star *}$ & $(1.0000)^{* *}$ & $(0.9997)^{\star *}$ & $(0.9484)^{* *}$ \\
& -24.5886 & -9.84071 & 220.689 & 235.832 \\
& $(0.0000)^{* *}$ & $(0.0000)^{* *}$ & $(0.0000)^{\star *}$ & $(0.0000)^{* *}$ \\
\hline
\end{tabular}

Note: $\Delta$ indicates first-order difference; ${ }^{* *}$ represents a significance level of $5 \%$. 
Table 3. Co-integration test (test results and test results).

\begin{tabular}{ccc}
\hline Statistical methods & Statistic & Statistics \\
\hline Perpdroni & Panel v-Statistic & $2.073606(0.0191)^{* *}$ \\
& Panel rho-Statistic & $-0.588827(0.2780)^{* *}$ \\
& Panel PP-Statistic & $-4.933536(0.0000)^{* *}$ \\
& Panel ADF-Statistic & $-4.473958(0.0000)^{* *}$ \\
& Group rho-Statistic & $1.883452(0.9702)^{* *}$ \\
& Group PP-Statistic & $-6.469837(0.0000)^{* *}$ \\
Kao & Group ADF-Statistic & $-7.932487(0.0000)^{* *}$ \\
Hypothesized No. of CE(s) & Fisher Stat. from tracetest $)$ & Fisher Stat.* (from max-eigentest) \\
None & A48.2(0.0000) & $422.5(0.0000)^{* *}$ \\
At most 1 & 136.1(0.0000) & $136.1(0.0000)^{* *}$
\end{tabular}

Table 4. Likelihood ratio (LR) test of panel data.

\begin{tabular}{cccc}
\hline Effects Test & Statistic & d.f. & Prob. \\
\hline Cross-section F & 30.857748 & $(30,209)$ & 0.0000 \\
Period F & 239.243284 & $(8209)$ & 0.0000 \\
\hline
\end{tabular}

that the model is appropriate to select the fixed-effect model.

\subsubsection{Model Selection}

Before the model is determined, the mixed model regression is first carried out to get the value of RRSS, and then the formula (2) in the theoretical basis is calculated to determine the final appropriate model for estimation. According to the calculation, we obtain the follow results:

$$
F=\frac{(197.804-3.036) / 248}{3.036 / 30}=7.7609
$$

the value of RRSS is 197.804 and that of URSS is 3.036 . And at the $5 \%$ confidence level, it's clear, so it's OK to choose the solid fixed effect model here. The regression results are shown in Table 5.

\section{Conclusions and Suggestions}

This paper uses stationary test, co-integration test and fixed effect regression estimation of panel data to study the impact of population change on economic growth. It's found that there is a long-term equilibrium relationship between the dependency ratio of the elderly population and economic growth GDP in 31 provinces and autonomous regions of China, and the influence of population changes in the top 18 provinces and autonomous regions on economic growth shows a positive correlation trend, especially in the top six cities, such as Heilongjiang, Liaoning and...., Zhejiang particularly significant. Moreover, it is not 
Table 5. Regression results of the model.

\begin{tabular}{cccccc}
\hline $\begin{array}{c}\text { Impact of EDR } \\
\text { on GDP }\end{array}$ & $\begin{array}{c}\text { Regional } \\
\text { rankings }\end{array}$ & $\begin{array}{c}\text { Impact of } \\
\text { EDR on GDP }\end{array}$ & $\begin{array}{c}\text { Regional } \\
\text { rankings }\end{array}$ & $\begin{array}{c}\text { Impact of } \\
\text { EDR on GDP }\end{array}$ & $\begin{array}{c}\text { Regional } \\
\text { rankings }\end{array}$ \\
\hline 3.613766 & Heilongjiang 1 & 0.912237 & Henan 13 & -2.035799 & Hainan 25 \\
3.449027 & Liaoning 2 & 0.796196 & Fujian 14 & -2.199992 & Qinghai 26 \\
3.396326 & Shandong 3 & 0.665445 & Tianjin 15 & -2.577146 & Yunnan 27 \\
3.385346 & Shanghai 4 & 0.417151 & Gansu 16 & -3.336375 & Guizhou 28 \\
3.14807 & Hebei 5 & 0.356245 & Ningxia 17 & -3.897913 & Xizang 29 \\
3.055012 & Zhejiang 6 & 0.324927 & Anhui 18 & -5.02428 & Chongqing 30 \\
2.811836 & Jilin 7 & -0.13057 & Shanxi 19 & -11.66585 & Guangxi 31 \\
2.452173 & Beijing 8 & -0.412568 & Hubei 20 & & \\
2.022946 & Shanxi 9 & -0.725591 & Xinjiang 21 & & \\
1.758254 & Neimenggu 10 & -0.829784 & Sichuan 22 & & \\
1.310668 & Guangdong 11 & -0.908233 & Hunan 23 & & \\
1.05112 & Jiangsu 12 & -1.182642 & Jiangxi 24 & & \\
\hline
\end{tabular}

difficult to see that the economic growth of Gansu, Ningxia and Anhui is less affected by population. Secondly, provinces and autonomous regions ranked from 19 to 31 show a negative correlation, among which Guangxi Province was particularly significant.

Therefore, in view of the above situation, several relevant suggestions are put forward:

1) Encourage fertility. In response to the Partly Central Committee's family planning policy, encourage people to have a second child, and fundamentally increase the number of labor force population.

2) Formulate scientific industrial adjustment policies to cater to the change of population structure. According to the population characteristics of our country, the government should formulate some targeted industrial adjustment strategies, so as to promote economic development.

3) Increase investment in human resources to provide a human base for high-quality economic development.

4) In view of the regional differences in the impact of population structure on economic growth, some regions can appropriately delay retirement.

\section{Funding}

This work is supported by the National Science Foundation of China (No. 11561056).

\section{Conflicts of Interest}

The authors declare no conflicts of interest regarding the publication of this paper. 


\section{References}

[1] You, S.B. and Cai, Y.F. (2017) Dynamic Analysis of the Impact of Population Aging on Economic Growth-Based on the Panel VAR Model. Economics and Management, 31, 22-29.

[2] Di, R.A.H. (2020) Discussion on the Impact of Population Aging on Economic and Social Development. Neijiang Science and Technology, 41, 138-139.

[3] Chen, J.M. (2020) Influencing Mechanism of Population Aging on Economic Growth in Guangdong Province: An Empirical Analysis Based on VECM Model. Journal of Guangdong Open University, 29, 28-34.

[4] Guo, H. and Ren, B.P. (2014) Demographic Dividend Change and Transformation of China's Economic Development Mode. Contemporary Finance and Economics, No. 3, 5-9.

[5] Chen, Q. (2015) Econometrics and Stata Application. Higher Education Press, Beijing.

[6] Yi, D.H. (2008) Data Analysis and EViews Application. University of China People's Press, Beijing. 